\title{
ALLOYS 625 AND 725: TRENDS IN PROPERTIES AND APPLICATIONS
}

\author{
Lewis E. Shoemaker \\ Huntington Alloys / Special Metals Corporation \\ 3200 Riverside Drive, Huntington, WV, 25705-1771, USA
}

\section{Keywords}

Alloy 625, UNS N06625, Alloy 625LCF, UNS N06626, Alloy 725, UNS N07725, Metallurgy, TTT Diagram, Precipitation Hardening, Microstructure, Fatigue, Welding, Fasteners, Strength

\begin{abstract}
INCONEL ${ }^{\circledR}$ alloy 625 (UNS N06625) has been widely used for over 50 years in the marine and petroleum industries for applications requiring high strength, fracture toughness, fabricability and resistance to corrosion. By increasing the titanium content of the alloy in the presence of its content of niobium, an alloy that can be significantly strengthened by heat treatment is created. By the precipitation of various secondary phases in an austenitic matrix, INCONEL alloy 725 (UNS N07725) offers the high strength of alloy 718 along with the corrosion resistance of alloy 625. The metallurgy of alloy 725 is discussed along with information about its properties, fabrication, and applications.
\end{abstract}

\section{Introduction}

The official life of INCONEL ${ }^{\circledR}$ alloy 625 (UNS N06625) began on December 8, 1964 with the issue of United States Patent Number 3,160,500 to Herbert L. Eiselstein and John Gadbut of the Huntington Alloys Products Division of the International Nickel Company in Huntington, West Virginia, USA. The unique properties of the new alloy described in the patent were its high tensile strength and resistance to creep and stress rupture at elevated temperatures. However, it has since proven to be a most versatile alloy with a variety of useful properties including resistance to corrosion by a wide variety of media including seawater and both oxidizing and reducing acids and salts, high fatigue strength, and excellent weldability and fabricability. Several variations of alloy 625 have been developed offering even more useful properties for some specific environments.

\begin{abstract}
Alloy 625
Alloy 625 was developed as a nickel-chromium alloy solid solution strengthened by its content of molybdenum and niobium. It was soon determined that the alloy had two main areas of application ... resistance to aqueous corrosion at ambient to slightly elevated temperatures and for high strength and resistance to creep, rupture, and corrosion at high temperatures. This resulted in the definition of two grades of the alloy that ASTM designated as grades 1 and 2. Grade 1 material is described as "annealed" and is intended for service up to $1100^{\circ} \mathrm{F}\left(593^{\circ} \mathrm{C}\right)$.

*INCONEL $®$ is a registered trademark of the Special Metals family of companies.
\end{abstract}


These products are normally annealed in the range of 1600 to $1800^{\circ} \mathrm{F}$ ( 871 to $982^{\circ} \mathrm{C}$ ) and exhibit a fine grain structure. Grade 2 products aredescribed as "solution annealed" and are intended for service at temperatures over $1100^{\circ} \mathrm{F}\left(593^{\circ} \mathrm{C}\right)$ when resistance to creep and rupture are needed. While ASTM specifications require a minimum annealing temperature of $2000^{\circ} \mathrm{F}\left(1093^{\circ} \mathrm{C}\right)$, products are normally annealed between 2050 and $2150^{\circ} \mathrm{F}$ and, thus, exhibit a coarse grain structure. This enhances the alloy's resistance to creep and rupture at high operating temperatures.

A recent advancement in the development of alloy 625-type products is a vacuum induction melted, controlled chemical composition, fine grain product that exhibits greatly improved fatigue resistance and thermal stability. Marketed as alloy $625 \mathrm{LCF}$, this grade has been issued the UNS number, N06626. Melting is closely controlled to produce a particularly clean microstructure. Thermal-mechanical processing is conducted to produce a fine grain size. This structure results in enhanced resistance to mechanical fatigue (Figure 1) and improved thermal stability. Alloy 625LCF exhibits excellent weldability and is used for fabrication of bellows and structures exposed to cyclic conditions at elevated temperatures.

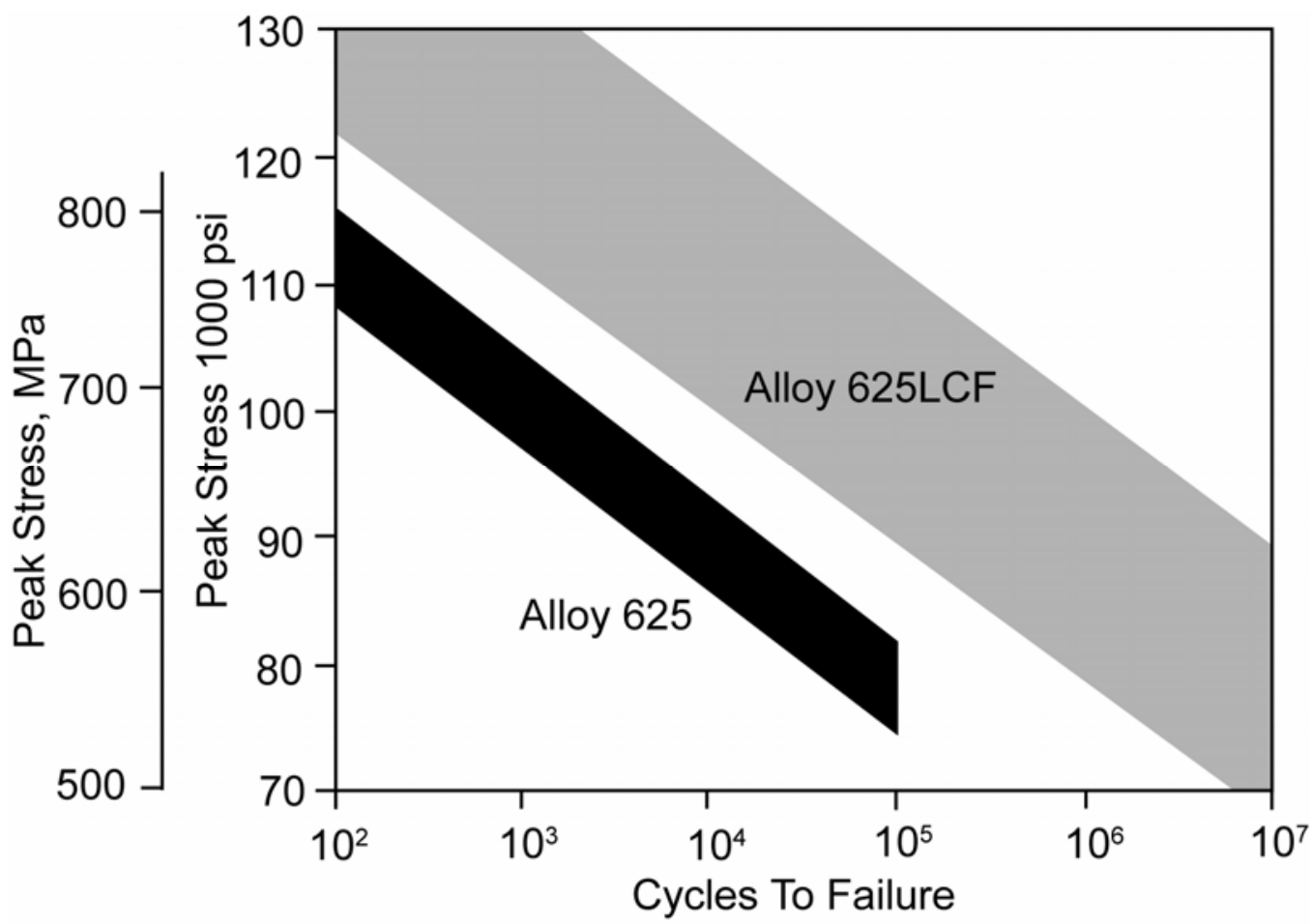

Figure 1 - Relative fatigue resistance - alloy 625 and alloy 625LCF at temperatures of 900 to $1200^{\circ} \mathrm{F}\left(480\right.$ to $\left.650^{\circ} \mathrm{C}\right)$ - push / pull tests with 5 ksi base stress

\section{Precipitation Hardening}

While alloy 625 was marketed as a solid solution strengthened alloy, with about 4\% niobium it was found to be somewhat age hardenable. When heated in the 1200 to $1600^{\circ} \mathrm{F}\left(649\right.$ to $\left.871^{\circ} \mathrm{C}\right)$ range, alloy 625 can precipitate a fine $\mathrm{Ni}_{3} \mathrm{Nb}$ dispersoid, $\gamma$ '. Various forms of carbide particles (principally $\mathrm{M}_{6} \mathrm{C}$ ) can also form (Figure 2). Recent studies by Radovich indicate that $\gamma$ ' may also form under some conditions. The effect of the combined precipitation of these phases is to significantly increase the yield and tensile strengths of the alloy. Annealed alloy 625 products typically exhibit tensile and yield strength values of $130 \mathrm{ksi}$ and $60 \mathrm{ksi}$, respectively. However, 
material aged at 1200 to $1250^{\circ} \mathrm{F}\left(649\right.$ to $\left.677^{\circ} \mathrm{C}\right)$ for extended periods of time (up to 100 hours) exhibit tensile strength over $160 \mathrm{ksi}$ and yield strength over $110 \mathrm{ksi}$.

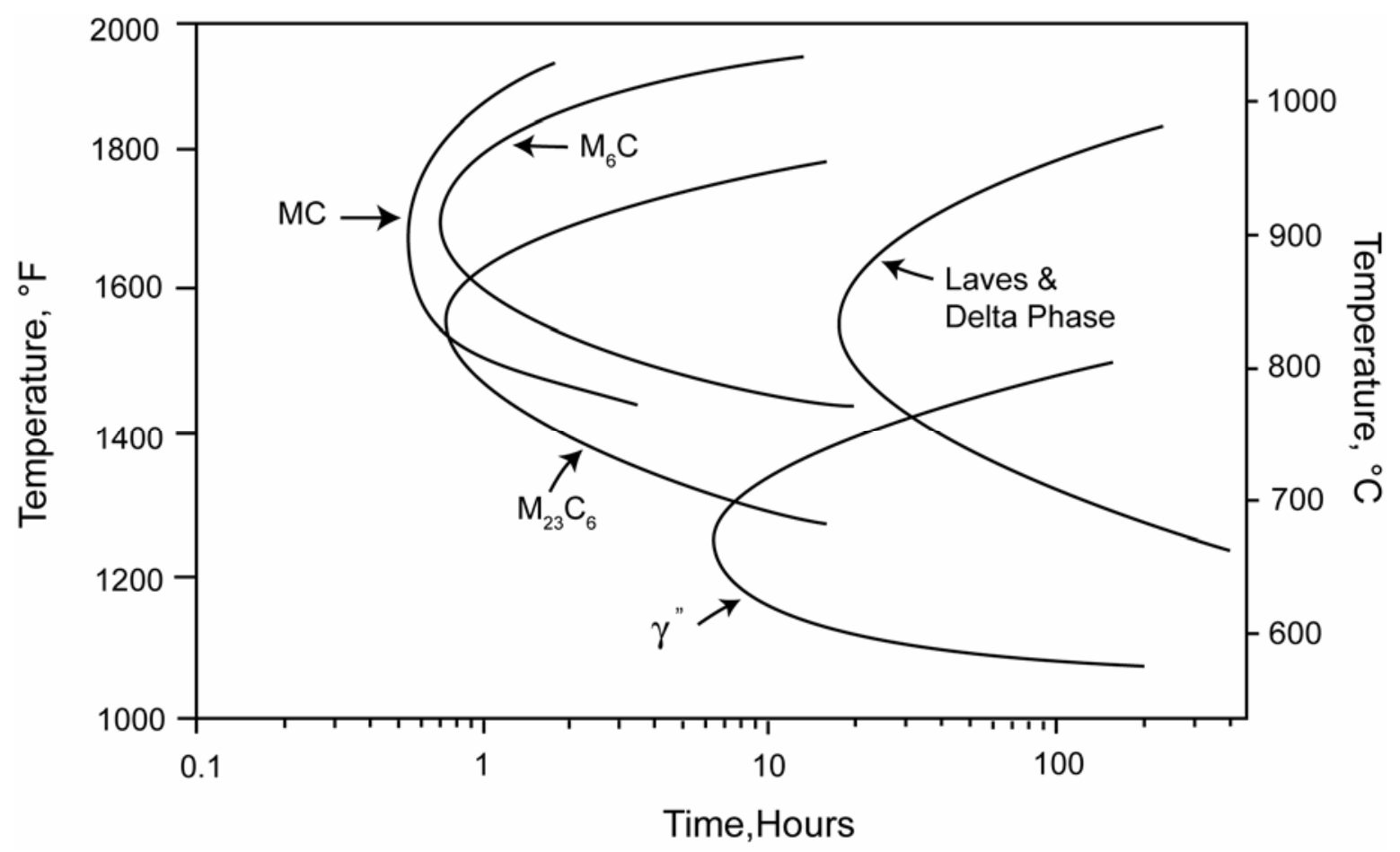

Figure 2 - Time-Temperature-Transformation Diagram - Alloy 625

The age hardening response of alloy 625 was further improved by the addition of titanium to produce a new alloy designated INCONEL ${ }^{\circledR}$ alloy 725 (UNS N07725). Alloy 725 exhibits essentially the same chemical composition (Table 1) as alloy 625 except that the titanium content is increased to about $1.5 \%$ to enhance precipitation hardening. Thus, it exhibits the excellent corrosion resistance of alloy 625 . In essence alloy 725 offers the excellent strength properties of alloy 718 with the proven corrosion resistance of alloy 625 . The time-temperature transformation diagram for alloy 725 is presented as Figure 3. It is seen that the precipitation contours for alloy 725 are similar to those for alloy 625 except that onset of precipitation of the $\gamma^{\prime}$ phase in alloy 725 occurs much more quickly than the precipitation of the $\gamma$ " phase in alloy 625 . Thus, the aging treatment required for alloy 725 is much more practical from a production standpoint than that for alloy 625.

Table 1 - Typical Chemical Composition - Alloys 625 \& 725

\begin{tabular}{|c|c|c|c|c|c|c|}
\hline Alloy & $\mathrm{Ni}$ & $\mathrm{Cr}$ & $\mathrm{Mo}$ & $\mathrm{Nb}$ & $\mathrm{Ti}$ & $\mathrm{C}$ \\
\hline 625 & 60 & 21 & 9 & 3.5 & 0.3 & 0.005 \\
725 & 58 & 21 & 9 & 3.5 & 1.5 & \\
\hline
\end{tabular}

As is seen in Figure 3, in addition to $\gamma^{\prime}$, a second phase, $\eta$, can also precipitate. It has been shown by Mannen, et.al. that this phase has a cumulative effect with $\gamma^{\prime}$ in strengthening alloy 725 . Figure 4 shows the microstructure of alloy 725 specially heat treated to precipitate both $\gamma^{\prime}$ and $\eta$ phases. While the typical yield strength of alloy 725 aged to precipitate only $\gamma^{\prime}$ is about $130 \mathrm{ksi}$, material heat treated to precipitate both $\gamma^{\prime}$ and $\eta$ phases, exhibits a typical yield strength level of $145 \mathrm{ksi}$. 


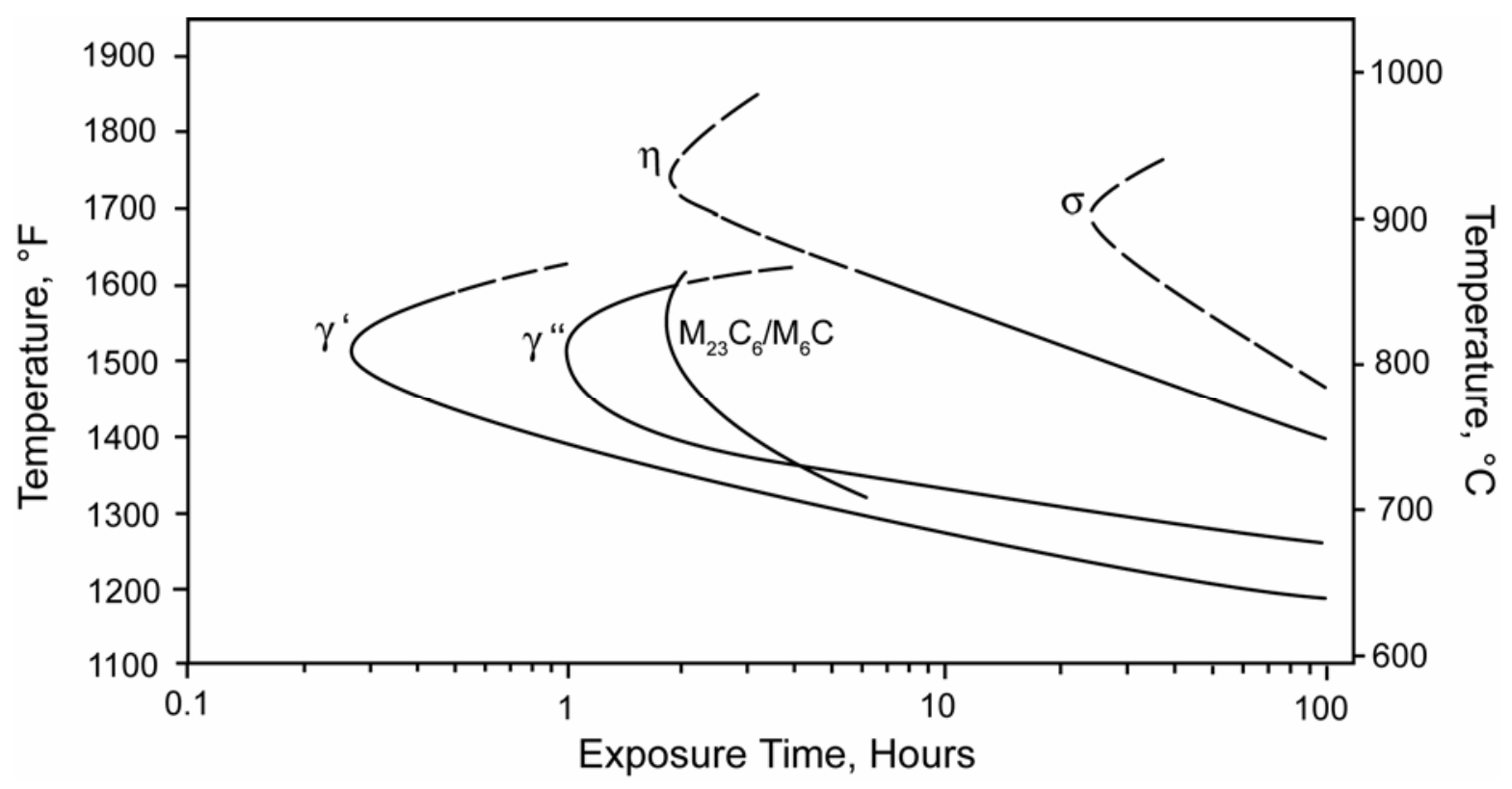

Figure 3 - Time-Temperature-Transformation Diagram - Alloy 725

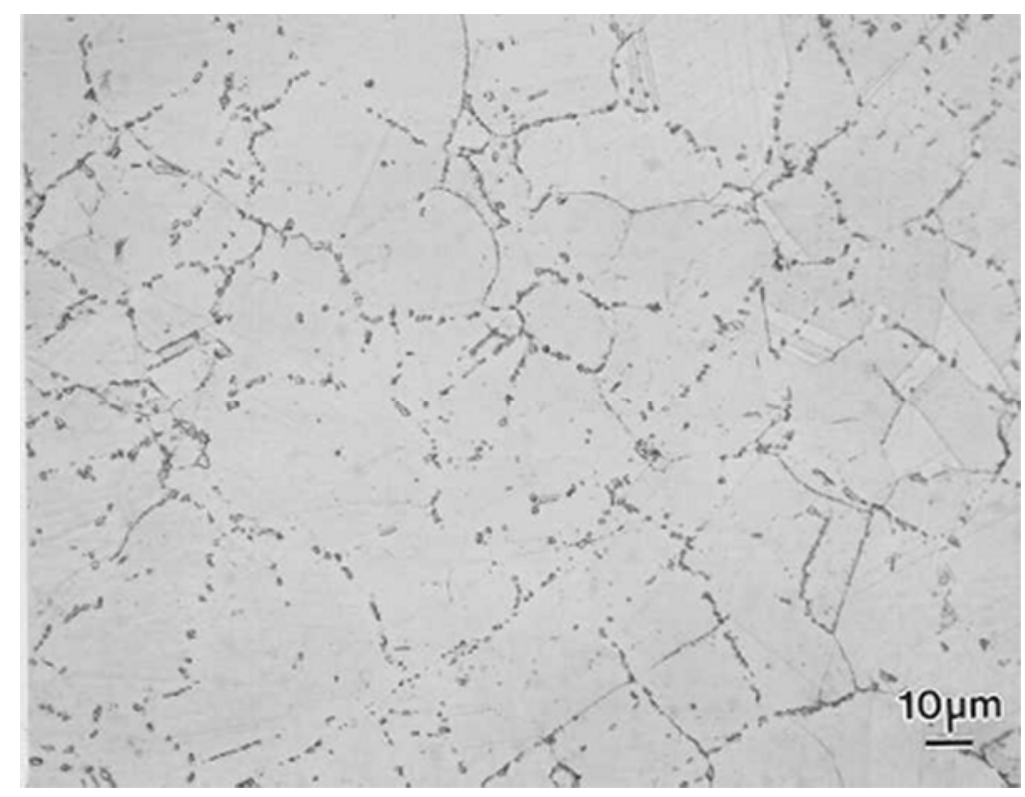

Figure 4 - Microstructure of alloy 725 heat treated to induce precipitation of eta phase to further strengthen the alloy matrix. Gamma prime constituent is too small to be seen at this magnification

\section{Applications ... alloy 625}

Alloy 625 which recently celebrated its $50^{\text {th }}$ "birthday", has been used for many varied applications. As noted earlier, the alloy offers strength, fatigue resistance, and resistance to aqueous corrosion for ambient to slightly elevated temperature service. And, it also offer strength and resistance to creep, rupture, and hot corrosion (especially oxidation and carburization at elevated temperatures. Alloy 625 also maintains good tensile strength, ductility, and impact and toughness properties at cryogenic temperatures. Alloy 625 offers excellent weldability and resistance to hot cracking. Thus it has become a quite popular welding composition. 
It is known that chromium imparts resistance to attack by oxidizing acids (e.g, nitric acid) and salts (e.g, ferric and cupric chloride) to nickel-base alloys. It is also known that molybdenum and niobium (and to a lesser extent, chromium) help define an alloy's resistance to attack by reducing acids (e.g, sulfuric and hydrochloric acids). With 22\% chromium, 9\% molybdenum and 3.5\% niobium, alloy 625 offers excellent resistance to both reducing, oxidizing, and mixed media. It also provides particularly good resistance to marine corrosion. Thus, alloy 625 (grade 1) is widely used for fabrication of shipboard components and associated support hardware.

Alloy 625 also offers properties that make it attractive for service at elevated temperatures. Chromium is the key element in giving a nickel-base alloy its resistance to corrosive attack at elevated temperatures (e.g, oxidation, carburization, and sulfidation). Molybdenum and niobium are especially effective in their role of strengthening an alloy at elevated temperatures. Thus, alloy 625 (grade 2) offers a desirable combination of strength and creep and rupture resistance along with resistance to corrosive attack at service temperatures up to about $2100^{\circ} \mathrm{F}\left(1140^{\circ} \mathrm{C}\right)$. Alloy 625 is one of the few alloys manufactured today for which the ASME Boiler and Pressure Vessel Code has defined allowable design stresses for service up to $1800^{\circ} \mathrm{F}\left(982^{\circ} \mathrm{C}\right)$.

The recuperator on the AGT 1500 gas turbine of the US M1 Abrams tank (Figure 5) has consumed large tonnages of alloy 625 over the past twenty years. The recuperator uses the heat from the engine exhaust to heat inlet air to $1000^{\circ} \mathrm{F}\left(538^{\circ} \mathrm{C}\right)$. The system operates under a pressure of about $200 \mathrm{psi}(1,350 \mathrm{Mpa})$ so any through-wall cracks would allow pressurized air to escape thereby reducing the amount of preheated air available to the engine and decreasing its overall efficiency. Work done by Special Metals Corporation and General Dynamics and reported by Smith, et.al. showed that vacuum melting substantially reduces total residue content of alloy 625 as compared to air melted material $(0.06 \%$ for VIM/ESR versus $0.42 \%$ for $\mathrm{EAF} / \mathrm{AOD} / \mathrm{ESR})$. This cleaner microstructure significantly improves the fatigue resistance of alloy 625LCF products and, thus, the service life of the components fabricated from the material. Bellows (Figure 6) are another good application of the LCF grade of alloy 625.

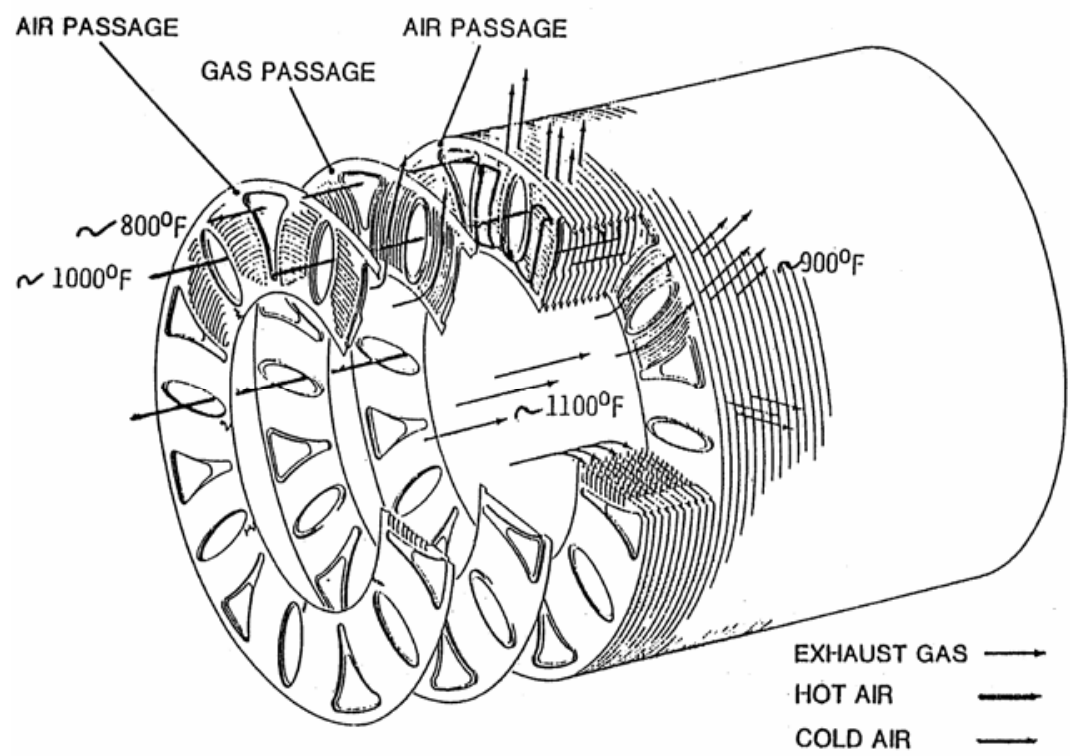

Figure 5 - Schematic of Alloy 625 heat recuperator for AGT 1500 turbine engine for the U.S. M-1 Abrams Tank. Fabrication of the components requires formability and weldability while the service requirements are high temperature strength and resistance to fatigue and abrasion. 


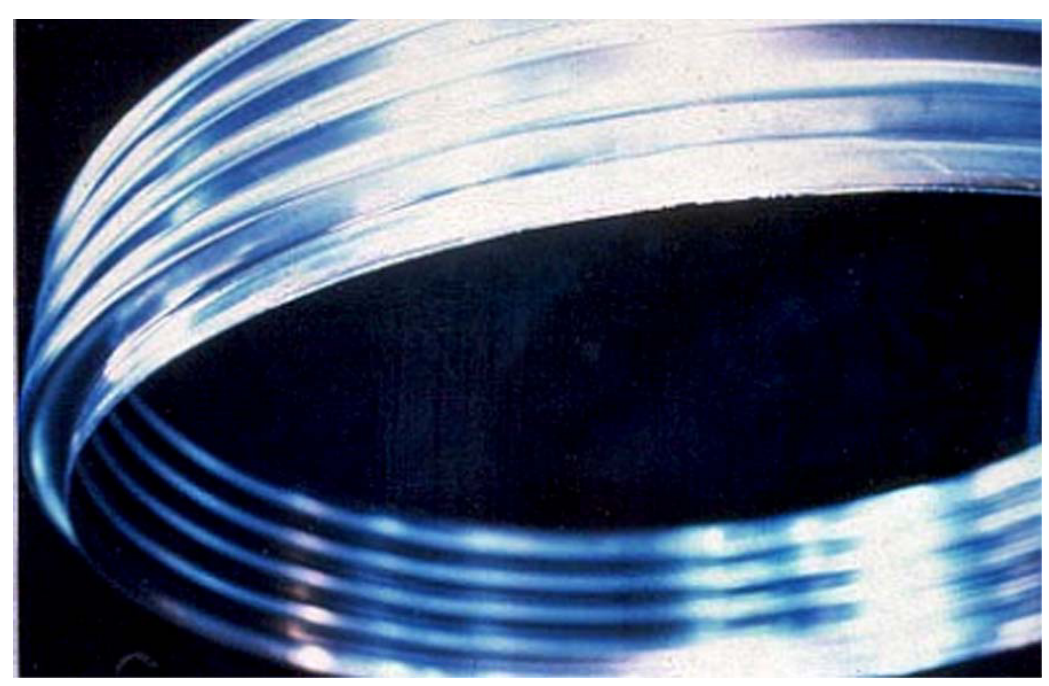

Figure 6 - Bellows fabricated from the 'LCF' grade of alloy 625 sheet utilize the alloy's strength, thermal stability, \& resistance to fatigue

Alloy 625 welding products are classified by the American Welding Society as ENiCrMo-3 and ERNiCrMo-3. The flux covered welding electrodes are used for shielded metal-arc welding (SMAW) while the bare filler metal can be used for gas metal-arc welding (GMAW), gas tungsten-arc welding (GTAW), and submerged arc welding (SAW). As with the base metal, alloy 625 welding products are used for applications at cryogenic, ambient, and elevated temperatures. The products' strength and toughness at cryogenic temperatures make the product popular for welding nickel steels (e.g, $3 \frac{1}{2} \%$ and $9 \%$ nickel grades) for service at sub-zero temperatures.

Alloy 625 products are particularly well suited for joining austenitic and super-austenitic stainless steels. Nickel-chromium-molybdenum and iron-nickel-chromium-molybdenum weldments experience elemental segregation upon solidification. This results in some parts of the weld structure being enriched in alloying elements while others are depleted. As a result, some areas have reduced resistance to corrosion. For this reason, weldments deposited with matching composition welding products may not offer corrosion resistance equivalent to that of the wrought base metal. To counter this effect, these corrosion-resistant materials are normally joined with over-matching composition welding products. Alloy 625 welding products are well suited for joining the molybdenum-bearing austenitic stainless steels (e.g, 316, 317, and 904L), the $6 \%$ molybdenum, nitrogen-enhanced super-austenitic stainless steels (alloy 25-6MO, AL6XN, 254SMO, etc.), and even the G-alloys. And, alloy 625 welding products are used for joining alloys for high temperature service. They obviously are the choice for joining alloy 625 products for high temperature operation. And, they have also been widely used for joining other high temperature alloys such as alloys $800 \mathrm{H}$ and $800 \mathrm{HT}, 802,330,601$, and others similar materials.

Alloy 625 welding products are widely used for overlay of alloy steel tubes in coal-fired power boilers and municipal waste incineration waste-to-energy boiler. Halides are especially aggressive corrodents for ferrous material at elevated temperatures. Alloy 625 welding products are often used for in-situ overlay of boiler tubes. And, recently procedures have been developed for shop overlay of boiler tubes prior to installation (Figure 7). Tubes overlaid with alloy 625 offer service life several times that of the unprotected steel tubes. 


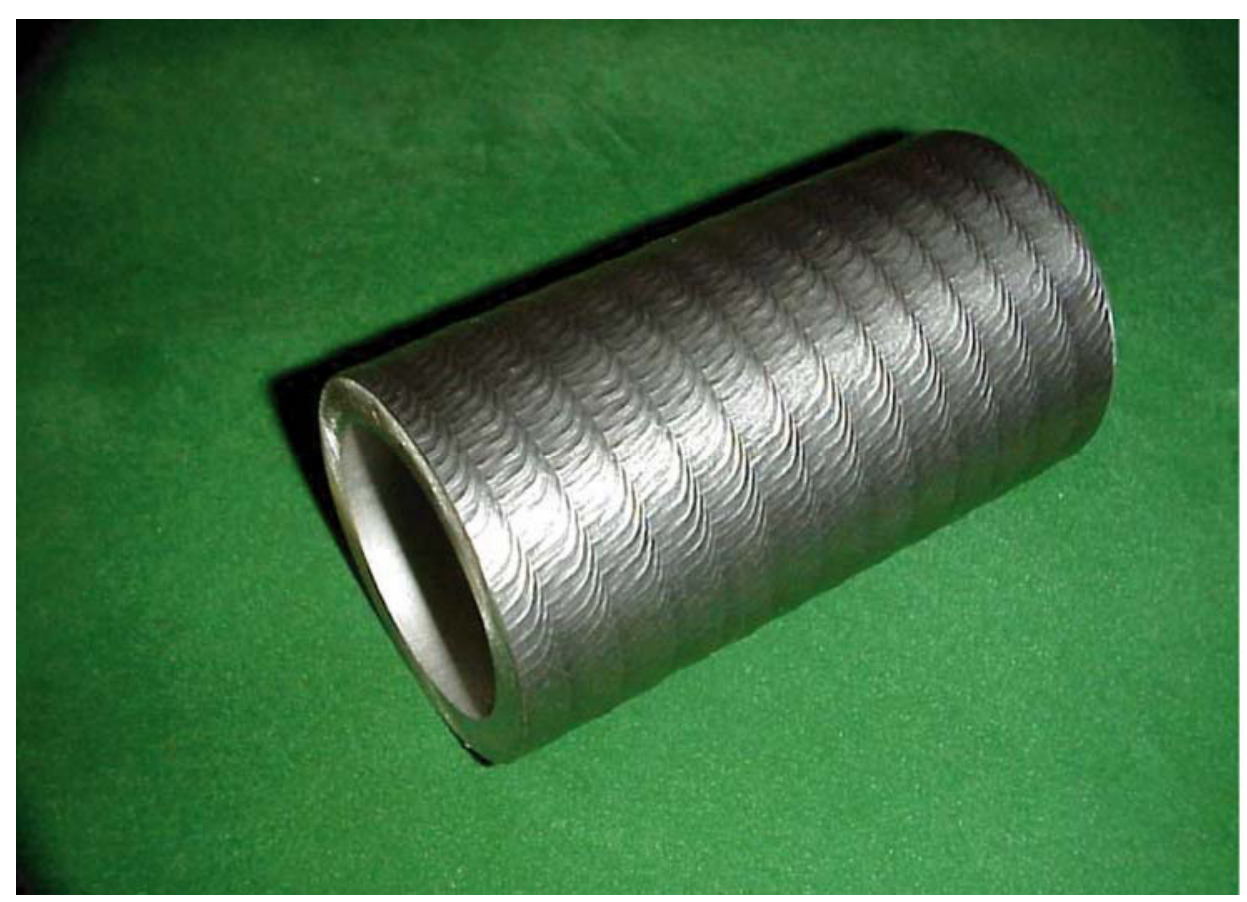

Figure 7 - Alloy Steel Boiler Tube Weld Overlaid with alloy 625

\section{Applications ... alloy 725}

Like its predecessor, alloy 725 has found a wide variety of applications. However, since the alloy is strengthened by precipitation hardening, it applications are normally limited to lower operating temperatures. The corrosion resistance of alloy 725 coupled with its high strength make it a candidate for applications in the marine, chemical processing, aerospace and oil and gas industries.

As previously stated, alloy 725 exhibits corrosion resistance equivalent to that of alloy 625 . Thus, it provides adequate resistance to corrosion in most marine and shipboard environments. In addition to its strength, alloy 725 also offers excellent fracture toughness. Before the advent of alloy 725 , marine designers were often limited to alloy 718 for a high strength alloy. However, alloy 718 only offers moderate resistance to marine corrosion and its fracture toughness is often lower than desired for "sub-safe" conditions. When heat treated to a yield strength of $150 \mathrm{ksi}$, alloy 718 normally exhibits a $\mathrm{K}_{\mathrm{IC}}$ fracture toughness of less than $50 \mathrm{ksi}$ sq. rt. in. While alloy 725 only develops yield strength levels of 120 to $130 \mathrm{ksi}$, it offers equivalent fracture toughness values in the range of 200 to $300 \mathrm{ksi}$. Alloy 725 offers a significant improvement in corrosion resistance and fracture toughness at a slightly lower level of strength. As a result, alloy 725 is a candidate for these applications which previously employed alloy 718 .

The high strength and toughness of alloy 725 makes it particularly well suited for fabrication of fasteners for marine applications (Figure 8). If even higher levels of strength are desired, it can be further enhanced by cold working prior to aging. The product is annealed, cold worked (generally by cold drawing), and then directly aged. In this manner yield strength levels over 180 ksi and tensile strength levels over $200 \mathrm{ksi}$ can be attained.

Alloy 725 may also be considered an upgrade to alloy K-500 (UNS N05500) which is commonly used for marine construction. Alloy K-500 is somewhat subject to hydrogen embrittlement when coupled to ferrous material and offers marginal strength and toughness for some applications. Alloy 725 improves upon all these shortcomings. 


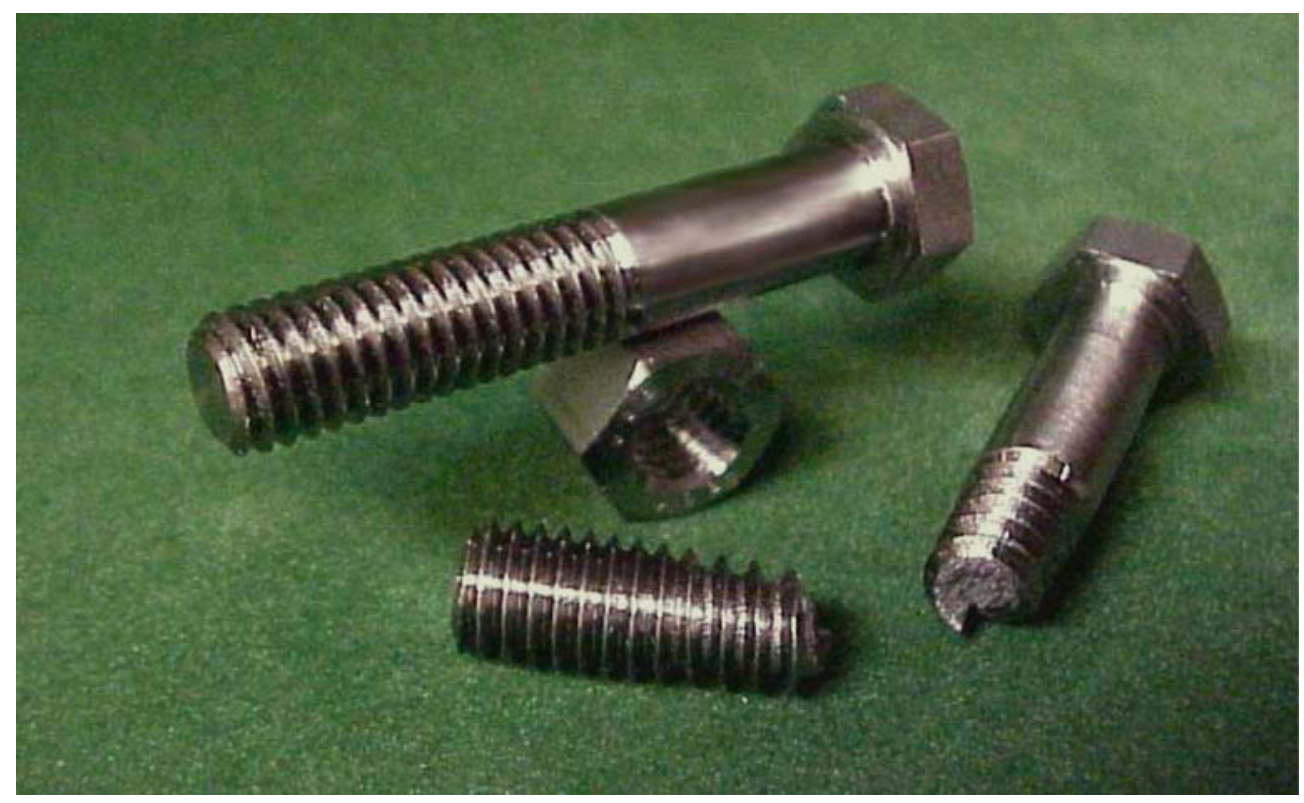

Figure 8 - Fasteners fabricated from high strength, corrosion-resistant materials such as alloys 625 and 725 are widely used in marine service. Their toughness is evident by the ductile fracture of the test bolt.

High strength and resistance to marine corrosion make alloy 725 a good candidate for marine hardware and power transfer components. The forgings shown in Figure 9 control the diving planes on a developmental military submarine.

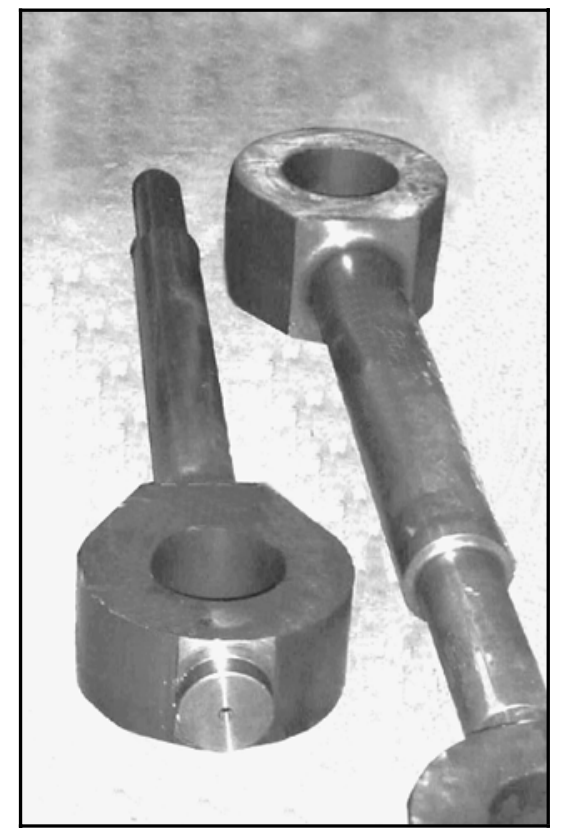

Figure 9 -Diving plane actuators for a military submarine forged from alloy 725 . Requirements of service are resistance to general and localized corrosion in seawater, strength and toughness.

Alloy 725 may be viewed as an upgrade for both alloys 718 and K-500 for oilfield applications. Many wells have sour conditions that can corrode all but the most resistant alloys. Corrodents include hydrogen sulfide, carbon dioxide, chlorides and free sulfur at high pressures and 
temperatures up to $450^{\circ} \mathrm{F}\left(232^{\circ} \mathrm{C}\right)$. Alloy 725 offers significant improvements in corrosion resistance and fracture toughness. Figure 10 shows a downhole hanger machined from alloy 725 bar. This component supports the entire weight the "string" of well casing. Alloy 725 is approved service in NACE MR0175 Environment Level 7 conditions.

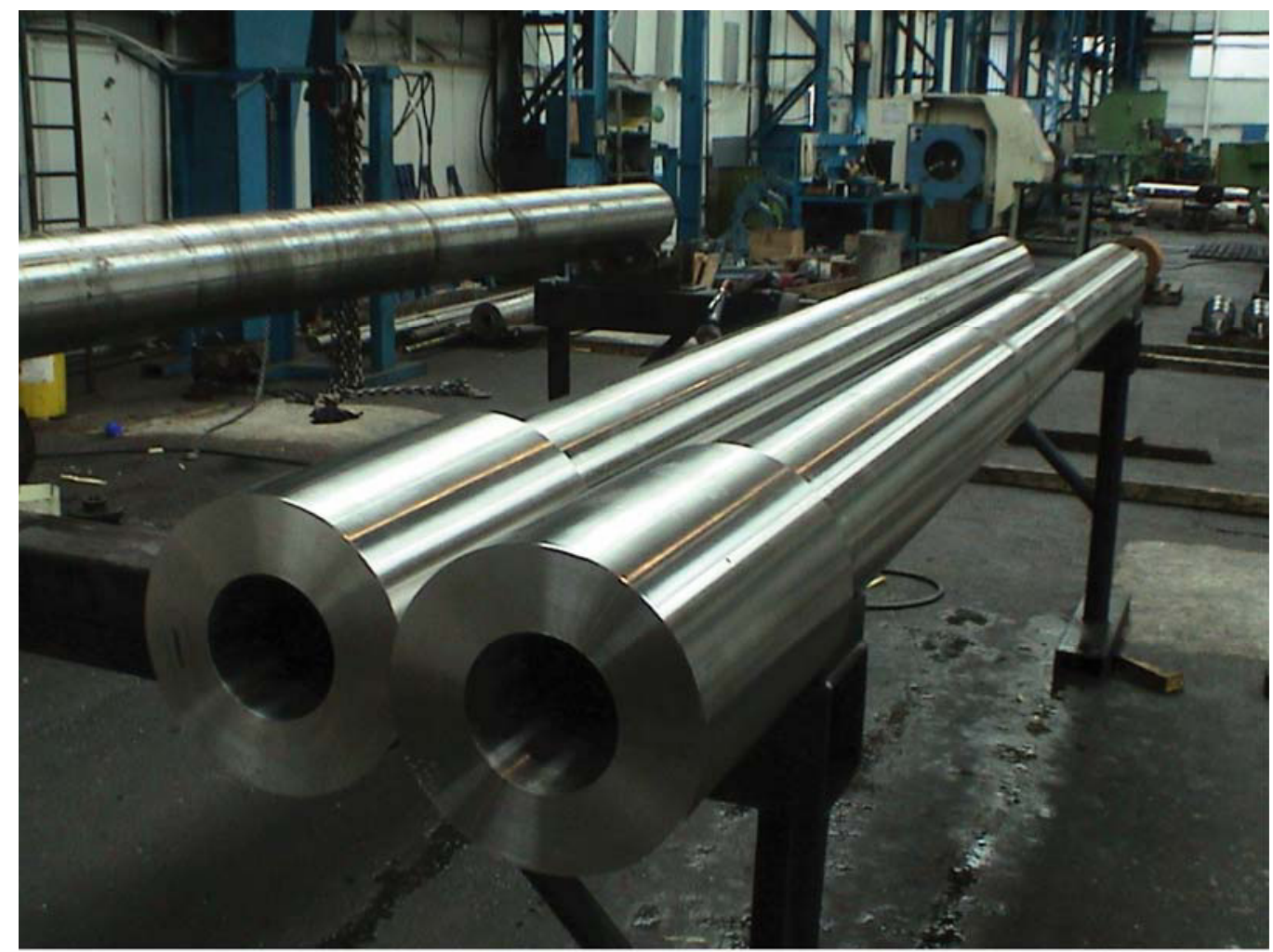

Figure 10 -Downhole hanger for an oil well machined from alloy 725 bar. This component must support the weight of the entire well casing. Requirements of service are high strength and resistance to general and localized corrosion under sour (acid halide $+\mathrm{H}_{2} \mathrm{~S}$ ) well conditions.

\section{Summary}

Over the past 50 years, alloy 625 has been widely used in many industries for numerous diverse applications over a wide temperature range from cryogenic conditions to ultra hot environments over $2000^{\circ} \mathrm{F}\left(1093^{\circ} \mathrm{C}\right)$. The alloy's strength and resistance to corrosion in both aqueous and high temperature environments along with its weldability and fabricability have made it the choice for many diverse applications. Its ability to resist oxidizing, reducing, and mixed acid environments make it a versatile alloy for use in many chemical processing, storage and transfer systems. Alloy 625 offers excellent resistance to attack in seawater and other marine environments. Thus, it is widely used for fabrication of marine and brine components as well as weld overlay of lesser alloy and steel parts.

Alloy 725 is in essence an age hardened version of alloy 625 differing mainly in its content of titanium which along with niobium, forms the hardening constituent, $\gamma$, when properly heat treated. When precipitation heat treated the alloy exhibits typical yield strength values of 120 to $130 \mathrm{ksi}$. This high strength along with corrosion resistance equivalent to alloy 625 makes alloy 725 a candidate for many new applications. Thus far, uses for alloy 725 have been identified in the oil and gas, marine, and chemical processing industries. The alloy's excellent $\mathrm{K}_{\mathrm{IC}}$ fracture 
toughness values make it a candidate for replacing alloy 718 in applications requiring toughness (e.g, sour oil and gas and marine applications).

While alloy 625 is over 50 years old, it continues to be the alloy of choice for many applications. And when one considers the unique properties offered by alloy 725 , it seems likely that it will be in use 50 years from now and well into the future.

\section{Bibliography}

Sarwan Mannan \& Frank Veltry, "Time-Temperature-Transformation Diagram of Alloy 725", Superalloys 718, 625, 706, and Various Derivatives, edited by E. A. Loria, TMS (The Mineral, Metals, and Material Society, 2001

Sarwan Mannan, Ed Hibner, \& Brett Puckett, "Physical Metallurgy of Alloys 718, 725, 725HS, and 925 for Service in Aggressive Corrosive Environments", Paper No. 03126, NACE Corrosion 2003, NACE International, Houston, TX, USA.

Stephen Floreen, Gerhard E. Fuchs, \& Walter J. Yang, "The Metallurgy of Alloy 625", Proceedings of the International Symposium on Superalloys 718, 625, 706, and Various Derivatives, Edited By Edward A. Loria, TMS / ASM / NACE, June 26/29, 1994.

G.D. Smith, J.R. Crum \& R.A. Smith, "Alloy Optimization for Enhanced Flexible Coupling Performance", Paper No. 960578, International Congress \& Exposition, SAE International, February 26-29, 1996, Detroit, MI, USA.

G.D. Smith, J.R. Crum \& W.B. Provan, "Optimizing Automobile Flexible Coupling Performance with INCONEL alloy 625LCF”, Paper No. 970702, International Congress \& Exposition, SAE International, February 24-27, 1997, Detroit, MI, USA.

G.D. Smith, M.J. Shaw, and R.K. Broyles, "Optimizing Metal Bellows Expansion Joint Performance in Refinery Applications", Stainless Steel World 99 Conference and Expo on Corrosion-Resistant Alloys, The Hague, November 17, 1999

Edward L. Hibner \& Lewis E. Shoemaker, "Innovative Nickel Alloys for Service in Critical Marine Applications", Paper No. 03259, Corrosion 2003, NACE International, Houston, TX, USA 